\title{
High Temperature Corrosion of Nickel in $\mathrm{NaVO}_{3}-\mathrm{V}_{2} \mathrm{O}_{5}$ Melts
}

\author{
J. Porcayo-Calderon, ${ }^{1}$ J. J. Ramos-Hernandez, ${ }^{2}$ Jan Mayén, ${ }^{3}$ E. Porcayo-Palafox, ${ }^{1}$ \\ G. K. Pedraza-Basulto, ${ }^{4}$ J. G. Gonzalez-Rodriguez, ${ }^{1}$ and L. Martinez-Gomez ${ }^{2,5}$ \\ ${ }^{1}$ CIICAp, Universidad Autónoma del Estado de Morelos, Avenida Universidad 1001, 62209 Cuernavaca, MOR, Mexico \\ ${ }^{2}$ Instituto de Ciencias Físicas, Universidad Nacional Autónoma de México, Avenida Universidad s/n, 62210 Cuernavaca, MOR, Mexico \\ ${ }^{3}$ CENIDET, Tecnológico Nacional de México, Prolongación Palmira s/n Esq. Apatzingán, Col. Palmira, \\ 62490 Cuernavaca, MOR, Mexico \\ ${ }^{4}$ Facultad de Ingeniería, UNACAR, 24180 Ciudad del Carmen, CAM, Mexico \\ ${ }^{5}$ Corrosion y Protección (CyP), Buffon 46, 11590 México City, Mexico
}

Correspondence should be addressed to J. Porcayo-Calderon; jporcayoc@gmail.com

Received 23 February 2017; Revised 12 May 2017; Accepted 25 May 2017; Published 22 June 2017

Academic Editor: Patrice Berthod

Copyright (C) 2017 J. Porcayo-Calderon et al. This is an open access article distributed under the Creative Commons Attribution License, which permits unrestricted use, distribution, and reproduction in any medium, provided the original work is properly cited.

\begin{abstract}
Many alloys used at high temperature in industrial processes are Ni-based and many others contain it in appreciable quantities, so it is of interest to evaluate the performance of pure nickel in order to determine the behavior of its alloys once the elements responsible for their protection have been depleted due to accelerated corrosion processes in the presence of vanadium-rich molten salts. Due to this, this work presents the study of $\mathrm{Ni}$ behavior in $\mathrm{NaVO}_{3}-\mathrm{V}_{2} \mathrm{O}_{5}$ mixtures at different temperatures. The behavior of pure nickel was determined by both electrochemical and mass loss measurements. The results show that the aggressiveness of the vanadium salts is increased by increasing both the $\mathrm{V}_{2} \mathrm{O}_{5}$ content and temperature. $\mathrm{V}_{2} \mathrm{O}_{5}$ addition considerably increases the current densities of the anodic and cathodic reactions. The corrosion process of $\mathrm{Ni}$ is modified due to the presence of its corrosion products, and its presence increases the activation energy by at least one order of magnitude. Although nickel shows a high reactivity in vanadiumrich salts, its reaction products are highly stable and protect it from the corrosive medium because the corrosion reactions trap the vanadium and block the migration of nickel ions.
\end{abstract}

\section{Introduction}

Many alloys for engineering applications at high temperature are Fe- or Ni-based. Their excellent mechanical properties and corrosion resistance make them useful for manufacturing components of industrial equipment such as industrial gas turbines and other energy conversion systems [1-6]. Corrosion resistance of alloys depends mainly on their chemical composition. In high temperature applications it is essential that the alloys be capable of developing protective oxides such as $\mathrm{Cr}_{2} \mathrm{O}_{3}, \mathrm{Al}_{2} \mathrm{O}_{3}$, or $\mathrm{SiO}_{2}$. Chemical and physical characteristics of this type of oxides, such as good adhesion, low gas permeability, high thermodynamic, and low diffusion coefficients, provide excellent protection to alloys in gaseous environments mainly [7-9].

However, the protection afforded by this type of oxide can be limited when molten phases are involved in the corrosion process. In these cases, the accelerated degradation of the materials may occur due to the so-called molten salt corrosion, hot corrosion, or high temperature corrosion. This type of corrosion is characterized by the accelerated degradation of the alloy when covered by a thin layer of molten salt at high temperature in an oxidant environment. In these cases, the integrity of any alloy will be compromised if its protective oxides do not show low solubility in the melt $[1,10,11]$.

The solubility of the protective oxides is greater in the presence of vanadium-rich fused salts (sulfate-vanadate type) than in pure $\mathrm{Na}_{2} \mathrm{SO}_{4}$; this is because the vanadate ions increase the acidic fluxing of any oxide [10]. On the other hand in $\mathrm{Na}_{2} \mathrm{SO}_{4}-\mathrm{V}_{2} \mathrm{O}_{5}$ mixtures the maximum solubility occurs in the interval 10 to $30 \% \mathrm{Na}_{2} \mathrm{SO}_{4}$ [12]. In many industrial systems where the use of heavy fossil fuels is common, the species causing the catastrophic corrosion of the materials 
are complex compounds of vanadium, $\beta$ and $\gamma$ sodium vanadates $\left(\mathrm{Na}_{2} \mathrm{O} \cdot \mathrm{V}_{2} \mathrm{O}_{4} \cdot 5 \mathrm{~V}_{2} \mathrm{O}_{5}\right.$ and $5 \mathrm{Na}_{2} \mathrm{O} \cdot \mathrm{V}_{2} \mathrm{O}_{4} \cdot 11 \mathrm{~V}_{2} \mathrm{O}_{5}$, resp.) being the most corrosive vanadium species [6, 12-14].

When accelerated corrosion decreases the concentration of the element responsible for forming the protective oxide, corrosion will proceed catastrophically if the rest of the elements of the alloy are unable to form stable corrosion products. For example, in most alloys the element responsible for forming a protective oxide is $\mathrm{Cr}$; however, in the presence of acidic vanadium salts it is not capable of forming a stable protective oxide [15].

Therefore, because many Ni-based superalloys show excellent corrosion resistance due to their ability to develop a protective oxide, $\mathrm{Cr}_{2} \mathrm{O}_{3}$, this study evaluates the performance of pure nickel in the presence of $\mathrm{NaVO}_{3}-\mathrm{V}_{2} \mathrm{O}_{5}$ mixtures from 600 to $900^{\circ} \mathrm{C}$. This is a model system (few reaction products, $\mathrm{NiO}$ and vanadates) in order to determine if this element would be able to provide some protection to the alloy once the element responsible for protection has been depleted.

\section{Experimental Procedure}

2.1. Corrosive Salts. The corrosive medium employed consisted of different $\mathrm{NaVO}_{3}: \mathrm{V}_{2} \mathrm{O}_{5}$ ratios, from pure $\mathrm{NaVO}_{3}$ to pure $\mathrm{V}_{2} \mathrm{O}_{5}$, and two intermediates ratios that promote the formation of the highly corrosive complex vanadates, namely, sodium $\beta$-vanadyl-vanadate $\left(\mathrm{Na}_{2} \mathrm{O} \cdot \mathrm{V}_{2} \mathrm{O}_{4} \cdot 5 \mathrm{~V}_{2} \mathrm{O}_{5}\right)$ and sodium $\gamma$-vanadyl-vanadate $\left(5 \mathrm{Na}_{2} \mathrm{O} \cdot \mathrm{V}_{2} \mathrm{O}_{4} \cdot 11 \mathrm{~V}_{2} \mathrm{O}_{5}\right)$. In previous studies these complex vanadates have been synthesized from the following ratios: $2 \mathrm{NaVO}_{3}: 5 \mathrm{~V}_{2} \mathrm{O}_{5}$ and $10 \mathrm{NaVO}_{3}: 7 \mathrm{~V}_{2} \mathrm{O}_{5}$, respectively [15], where $\mathrm{NaVO}_{3}$ is the vanadium salt with the highest basicity, $\mathrm{V}_{2} \mathrm{O}_{5}$ is the compound with the highest acidity, and $2 \mathrm{NaVO}_{3}: 5 \mathrm{~V}_{2} \mathrm{O}_{5}$ and $10 \mathrm{NaVO}_{3}: 7 \mathrm{~V}_{2} \mathrm{O}_{5}$ ratios are compounds with intermediate acidity and high oxygen adsorption capacity. Since the $\mathrm{NaVO}_{3}$ can be synthesized from the $\mathrm{Na}_{2} \mathrm{O}: \mathrm{V}_{2} \mathrm{O}_{5}$ ratio, it is considered that by increasing the molar ratio of $\mathrm{V}_{2} \mathrm{O}_{5}$ the acidity of the resulting compound increases. For simplicity, hereafter the above-mentioned compounds will be identified according to the following nomenclature: $\mathrm{NV}$ is $\mathrm{NaVO}_{3}, \mathrm{NV} 3$ is sodium $\gamma$-vanadyl-vanadate, NV6 is sodium $\beta$-vanadylvanadate, and $\mathrm{V}$ is $\mathrm{V}_{2} \mathrm{O}_{5}$, where $\mathrm{N}$ is $\mathrm{Na}_{2} \mathrm{O}$. Its known melting points are $630^{\circ} \mathrm{C}, 627^{\circ} \mathrm{C}, 535^{\circ} \mathrm{C}$, and $691^{\circ} \mathrm{C}$, respectively [14].

2.2. Electrochemical Measurements. Electrochemical evaluations were performed using a three-electrode arrangement. As pseudo-reference electrode and counter electrode a platinum wire was used. Nickel samples were spot-welded with a $\mathrm{Ni20Cr}$ wire in order to get electrical connection. Ni20Cr wire was isolated with a ceramic tube and sealed with refractory cement. The test temperatures selected were 700 , 800 , and $900^{\circ} \mathrm{C}$, which are above the melting point of the salts. The test temperature was measured constantly, using a type $\mathrm{K}$ thermocouple and was controlled to $2^{\circ} \mathrm{C}$ with respect to the test temperature. Before starting the electrochemical measurements, the electrode array is immersed in the molten salt and the open-circuit potential of the working electrode is measured until steady state $( \pm 5 \mathrm{mV})$ is reached; in all cases this was achieved in about 30 minutes. In all experiments, the atmosphere above the melt was static air. Potentiodynamic polarization curves and linear polarization resistance (LPR) measurements were carried out. Potentiodynamic polarization curves were obtained polarizing the working electrode from -300 to $300 \mathrm{mV}$ at scanning rate of $1 \mathrm{mV} / \mathrm{s}$, and the electrochemical parameters (Tafel slopes, $E_{\text {corr }}$ and $I_{\text {corr }}$ ) were obtained from the active regions of the corresponding anodic and cathodic zones. LPR measurements were obtained applying a potential of $\pm 10 \mathrm{mV}$, and the variation in current intensity associated with that polarization was measured during $24 \mathrm{hr}$. An ACM Instrument potentiostat, model GillAC, controlled by a personal computer was used for the electrochemical experiments.

2.3. Mass Loss Corrosion Testing. Before mass loss tests, the specimens were cleaned with acetone and dried, subsequently weighed by means of an analytical digital scale with a precision of $0.00001 \mathrm{~g}$, and then packed in the mixture of salts in porcelain crucibles with $500 \mathrm{mg} / \mathrm{cm}^{2}$ of vanadium salts. The corrosion tests were carried out in electric furnaces in static air during 100 hours at temperatures of 700, 800, and $900^{\circ} \mathrm{C}$. Four specimens were exposed to each test condition. After corrosion tests the corrosion rate was measured as mass loss. Three specimens of each condition test were descaled and chemically cleaned according to ASTM G1 standard, and the other specimen was mounted in thermosetting resin in cross section and polished to analyze the subsurface corrosive attack using a Karl Zeiss DSM-950 scanning electronic microscope (SEM) with an X-ray energy dispersive (EDS) analyzer. In short, the specimen descaling was realized mechanically with a cutter in order to remove the coarse and soft layers of products of corrosion; subsequently the heavily adhered corrosion products were removed by chemical cleaning in a solution of $15 \%$ hydrochloric acid (v/v) at room temperature with immersion times of 3 minutes, and cleaning by light brushing until the complete removal of the corrosion products (constant weight of the metal).

In all cases high purity $\mathrm{Ni}(99.9 \%)$ was used. Ni specimens were obtained from rectangular bars and cut in samples with dimensions of $10 \times 5 \times 5 \mathrm{~mm}$. In order to obtain a homogeneous and defined reaction area, specimens were polished with silicon carbide sandpaper to grade 600 . Subsequently, the specimens were washed with distilled water and acetone before performing the corrosion tests.

\section{Results and Discussion}

3.1. Polarization Curves. Figures 1-3 show the potentiodynamic polarization curves for $\mathrm{Ni}$ in the different vanadium salts at 700,800 , and $900^{\circ} \mathrm{C}$, respectively. It is observed that, in the presence of NV3, NV6, and V, at all test temperatures, the Ni polarization curves were shifted to higher current densities and nobler potentials than those observed in NV. No significant variation in $E_{\text {corr }}$ values was observed in the presence of NV3, NV6, and V, at all test temperatures. In all cases, by increasing the vanadium content in the salt an increase in the current densities of the anodic and cathodic 


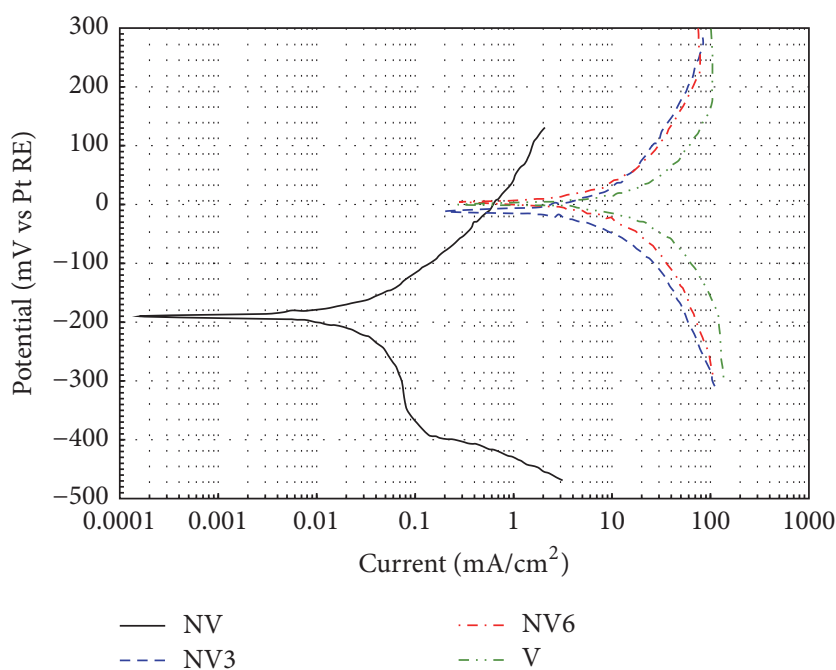

Figure 1: Potentiodynamic polarization curves for Ni in NV, NV3, $\mathrm{NV} 6$, and $\mathrm{V}$ at $700^{\circ} \mathrm{C}$.

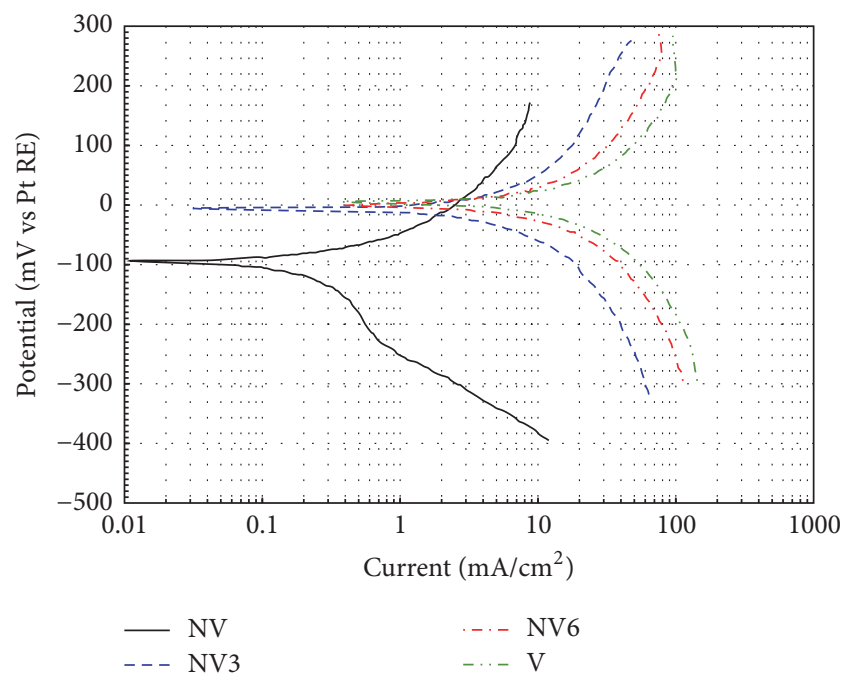

Figure 2: Potentiodynamic polarization curves for Ni in NV, NV3, $\mathrm{NV6}$, and $\mathrm{V}$ at $800^{\circ} \mathrm{C}$.

branches was observed. This difference is most noticeable as the temperature increases.

The observed behavior is associated with the conductive nature of the vanadium salts, because in the molten state the vanadium salts act as electronic conductors or ionic conductors [16]. The conductive nature of the vanadium salts depends on the $\mathrm{Na}_{2} \mathrm{O}$ concentration, $\mathrm{V}^{5+} / \mathrm{V}^{4+}$ ratio, and oxygen partial pressure, such that by increasing the $\mathrm{Na}_{2} \mathrm{O}$ concentration the ionic conduction increases, and by increasing the $\mathrm{V}^{5+} / \mathrm{V}^{4+}$ ratio and the partial pressure of oxygen, the electronic conduction increases. Because vanadium can coexist in different oxidation states (the most stable oxidation states are $+5,+4$, and +3 ), the aggressiveness of the vanadium salts increases by increasing the $\mathrm{V}^{5+}$ proportion (higher concentration of $\mathrm{V}_{2} \mathrm{O}_{5}$ ) and the partial pressure of oxygen (higher oxidation state of vanadium is favored); on the other hand, its aggressiveness is reduced by

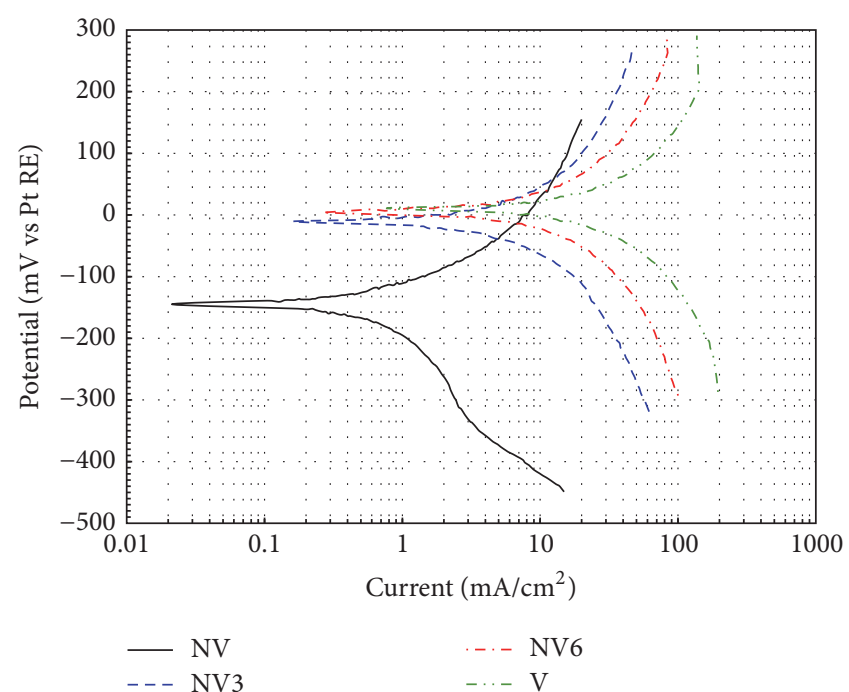

Figure 3: Potentiodynamic polarization curves for Ni NV, NV3, $\mathrm{NV} 6$, and $\mathrm{V}$ at $900^{\circ} \mathrm{C}$.

increasing the concentration of $\mathrm{Na}_{2} \mathrm{O}$, due to an increase in the proportion of $\mathrm{V}^{+4}$ and $\mathrm{V}^{+3}$ (increase in melt basicity) $[11,17,18]$. Therefore, the presence of these multivalent ions enhanced the charge transport through the melt either by counterdiffusion of multivalent cations or electron hopping [11].

From the current corrosion densities calculated from Figures 1-3, the effect of the NV: V ratio and temperature on the nickel corrosion rate was determined. Figure 4 shows the effect of $\mathrm{NV}: \mathrm{V}$ ratio and temperature on $\mathrm{Ni}$ corrosion rate. Although the corrosiveness of the salts NV3 and NV6 shows little difference, it is clear that the aggressiveness of the melt increases by increasing its acidity (higher proportion of $\mathrm{V}^{+5}$ ) and temperature, and the contrary happens by increasing its basicity (higher concentration of $\mathrm{Na}_{2} \mathrm{O}$ ). Similar trends have been observed in studies using chromium [15]. In particular, the NV3 and NV6 compounds have little difference in their V content, and they have been considered as the only vanadium species with the highest oxygen absorbing capacity $[12,19]$. The increase in the aggressiveness of the molten salts by increasing the $\mathrm{V}$ concentration is congruent with previous reports indicating that the $\mathrm{V}_{2} \mathrm{O}_{5}$ catalyzes the oxidation reaction of $\mathrm{Ni}[20]$.

3.2. LPR Measurements. Figures 5-7 show the $I_{\text {corr }}$ variation (from LPR measurements) with time for $\mathrm{Ni}$ in the different vanadium salts from 700 to $900^{\circ} \mathrm{C}$. The observed trends are similar to all test temperatures; namely, there is a strong variation in the $I_{\text {corr }}$ values in the first two hours of test and subsequently a pseudo-stationary state is reached. This behavior shows the high reactivity of $\mathrm{Ni}$ in the vanadium salts and that the corrosion products formed are highly protective. In all cases, the vanadium salts corrosiveness increases with both the melt acidity and temperature, and again, it is observed that the NV3 and NV6 species show little difference in their degree of aggressiveness. Figure 8 shows the appearance of the corrosion front of Ni evaluated in NV3 


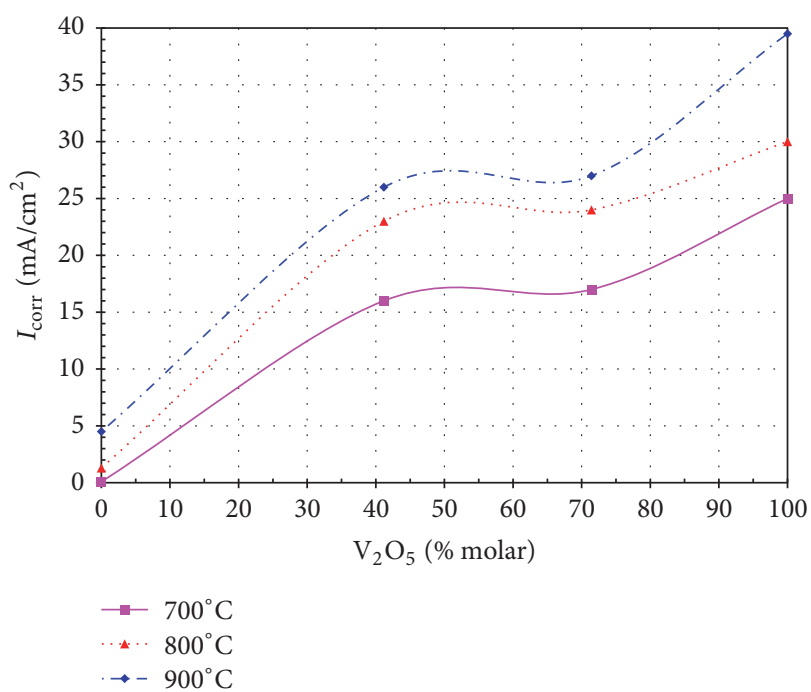

(a)

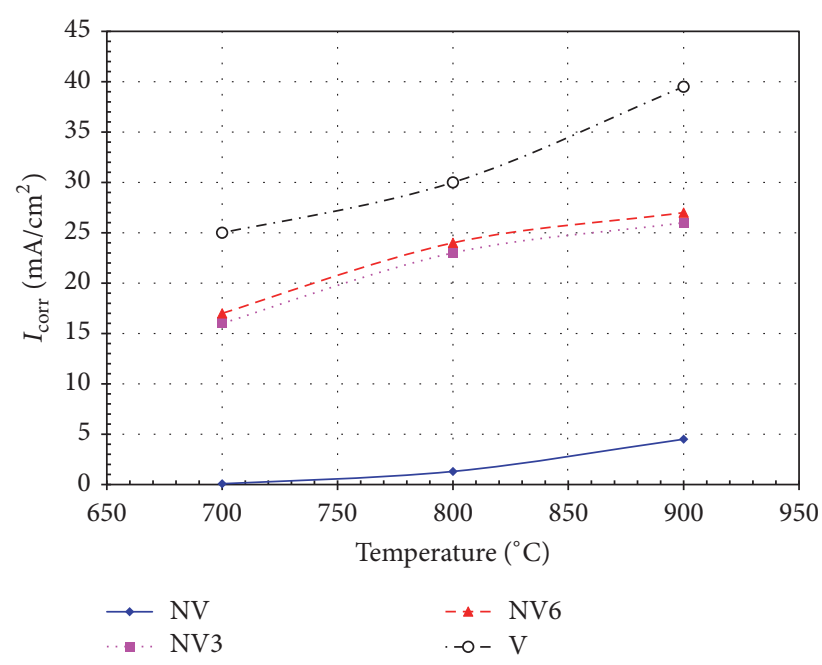

(b)

FIGURE 4: Effect of NV: V ratio (a) and temperature (b), on Ni corrosion rate.

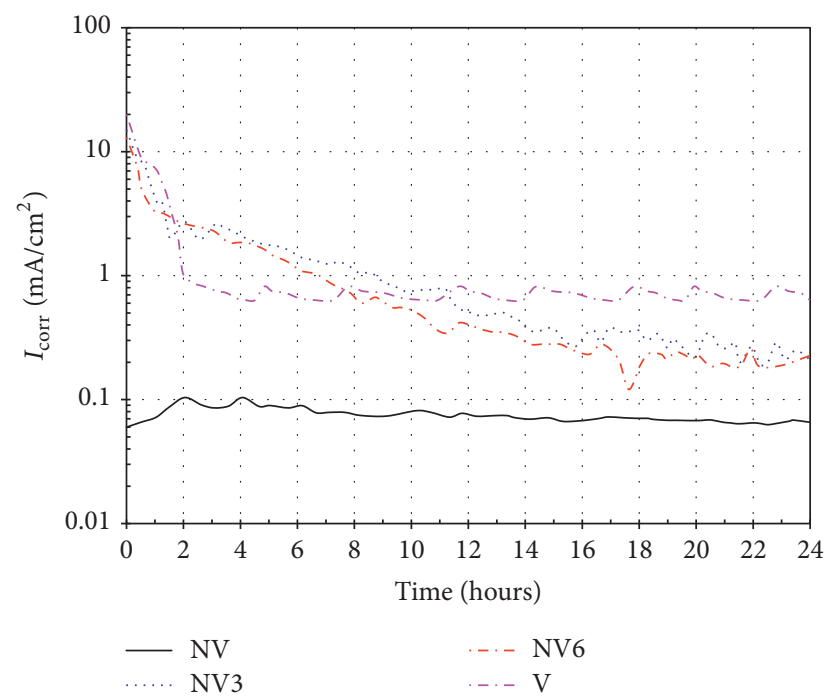

FIgURE 5: $I_{\text {corr }}$ variation versus time for $\mathrm{Ni}$ in $\mathrm{V}$-rich molten salts at $700^{\circ} \mathrm{C}$.

at $800^{\circ} \mathrm{C}$. A similar behavior was observed at all temperatures and with the different vanadium salts.

In almost all cases a thin film rich in oxygen and nickel $(\mathrm{NiO})$ onto $\mathrm{Ni}$ surface and a thick and dense layer of corrosion products rich in $\mathrm{Ni}-\mathrm{V}-\mathrm{O}$ onto the thin film were observed. Corrosion products showed a defined form of crystals growing either from the Ni surface or from the $\mathrm{NiO}$ film towards the melt. On the other hand, the presence of $\mathrm{Ni}$ was not observed in the vanadium-rich zone. All this is congruent with the tendency of the LPR values; that is to say, after the initial attack (first hours of immersion) the corrosion products formed a protective barrier that limited the access of the vanadium salts to the Ni surface.

In order to evaluate if there was a change in the corrosion process kinetics between the information obtained from the

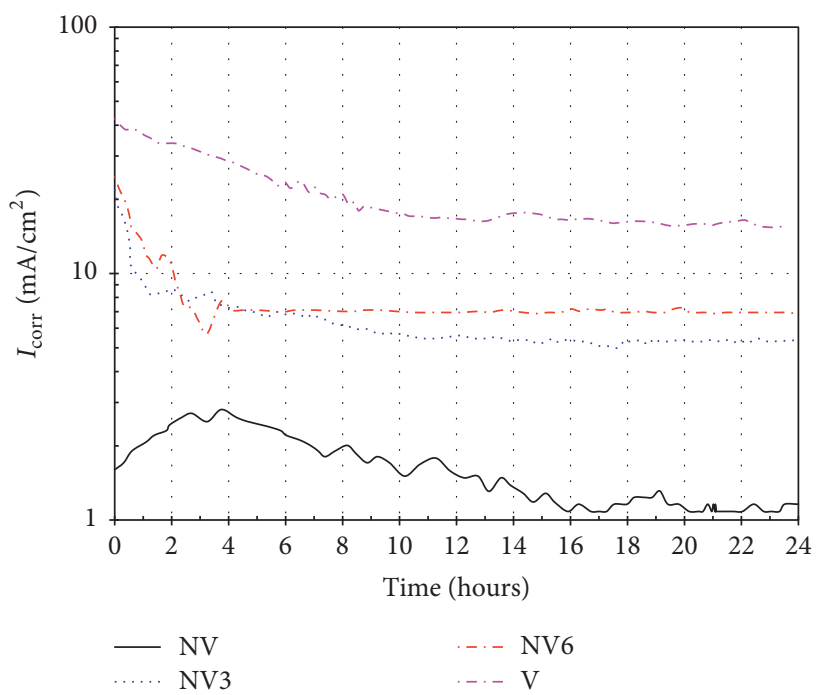

FIGURE 6: $I_{\text {corr }}$ variation versus time for $\mathrm{Ni}$ in V-rich molten salts at $800^{\circ} \mathrm{C}$.

polarization curves and LPR measurements, the activation energies were determined based on the $I_{\text {corr }}$ values obtained from both tests. In the case of the $I_{\text {corr }}$ values obtained from the LPR tests, the average of the last 4 hours of test was considered. The dependence between corrosion rate and temperature can be obtained from the Arrhenius equation:

$$
\begin{aligned}
I_{\text {corr }} & =k \exp \left(-\frac{\Delta E}{R T}\right), \\
R \ln \left(I_{\text {corr }}\right) & =R \ln k-\frac{1}{T} \Delta E
\end{aligned}
$$

where $\Delta E\left(\mathrm{~J} \mathrm{~mol}^{-1}\right)$ is the activation energy, $k$ is a constant, and $R$ is the gas constant $(8.314472 \mathrm{~J} / \mathrm{K}-\mathrm{mol})$. Figure 9 shows the $R \ln \left(I_{\text {corr }}\right)$ versus $1 / T$ relationship of the 


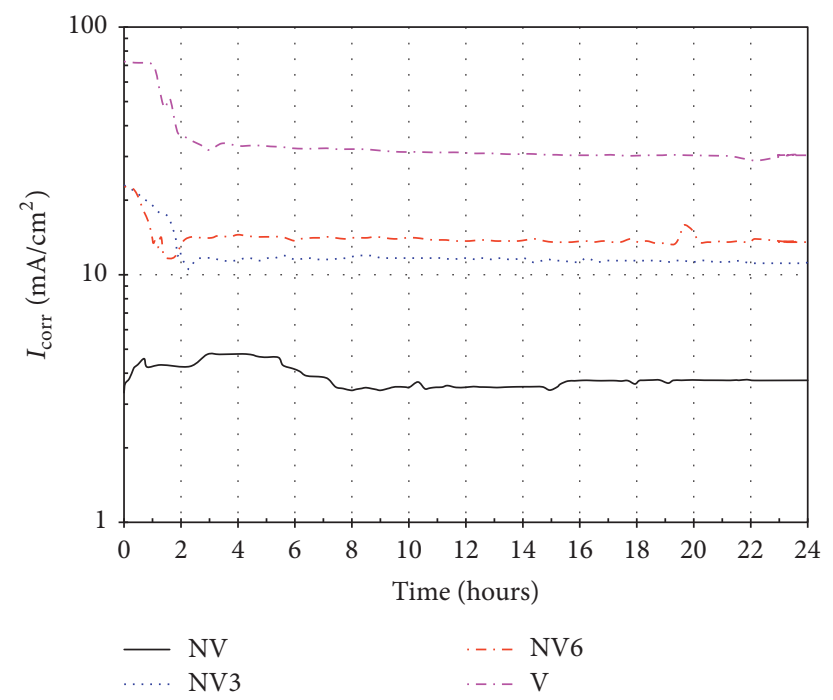

FIGURE 7: $I_{\text {corr }}$ variation versus time for Ni in V-rich molten salts at $900^{\circ} \mathrm{C}$.

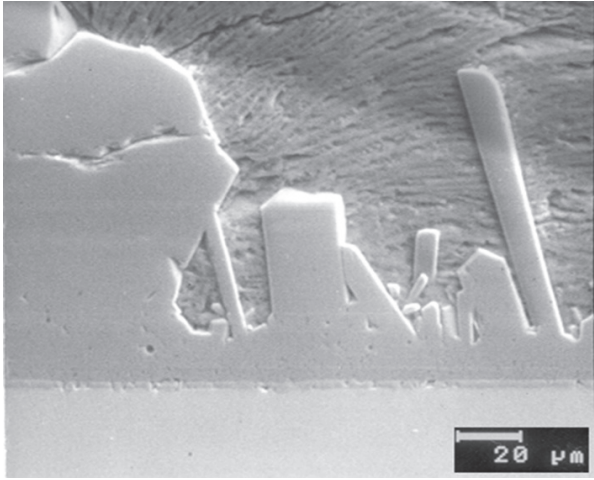

Image of secondary electrons

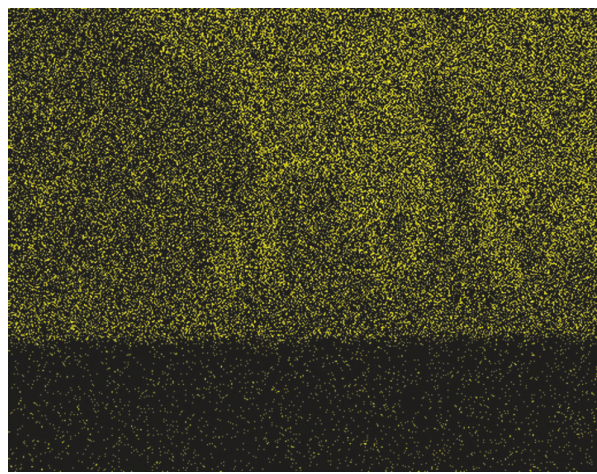

Vanadium



$\mathrm{Ni}$

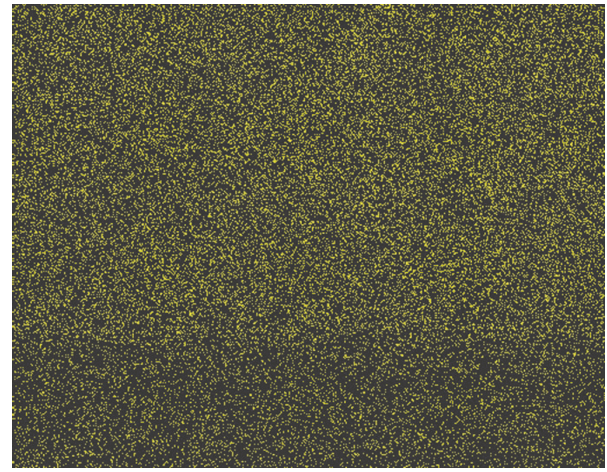

Oxygen

FIgURE 8: Cross sectional aspect of $\mathrm{Ni}$ and element mapping, after LPR measurements in NV3 at $800^{\circ} \mathrm{C}$ for 24 hours.

$I_{\text {corr }}$ values obtained from the potentiodynamic polarization curves and the LPR measurements. In the first case the information derived from the potentiodynamic polarization curves corresponds to the interaction of the bare $\mathrm{Ni}$ surface with the molten salts, and in the second case due to the corrosion process of $\mathrm{Ni}$ with corrosion products adhered to its surface (NiO and nickel vanadates). In the case of a bare Ni surface, the activation energies determined were
193, 23, 22, and $21.5 \mathrm{~kJ} \mathrm{~mol}^{-1}$ for NV, NV3, NV6, and V, respectively. These values show that the Ni corrosion rate increases with the vanadium content of the molten salts and that the corrosiveness of the NV3, NV6, and V is at least one magnitude order greater than that of the NV. In contrast, the activation energy values after 20 hours of corrosion varied between 181 and $202 \mathrm{~kJ} \mathrm{~mol}^{-1}$ for the different vanadium salts. The corrosiveness of the NV did not change significantly, 


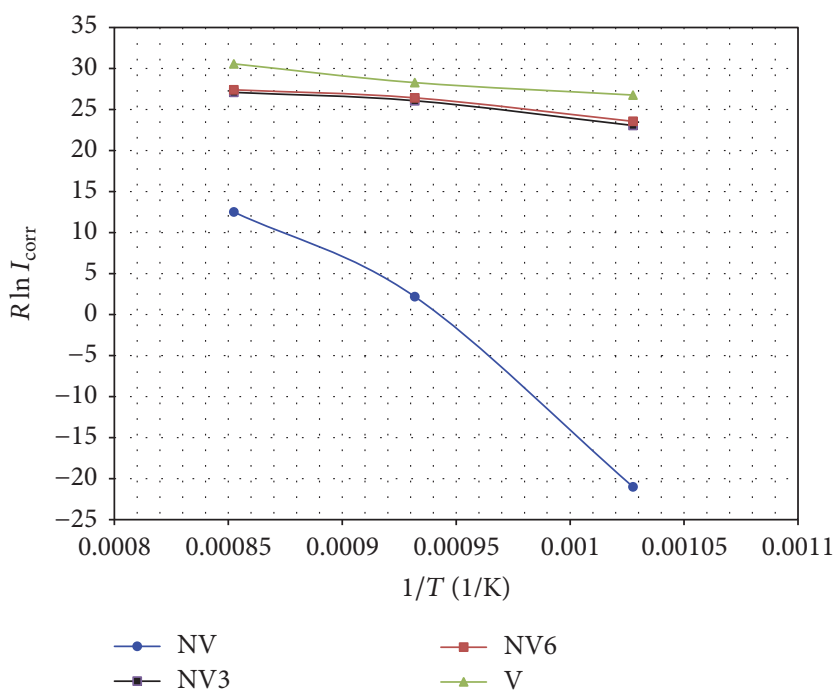

(a)

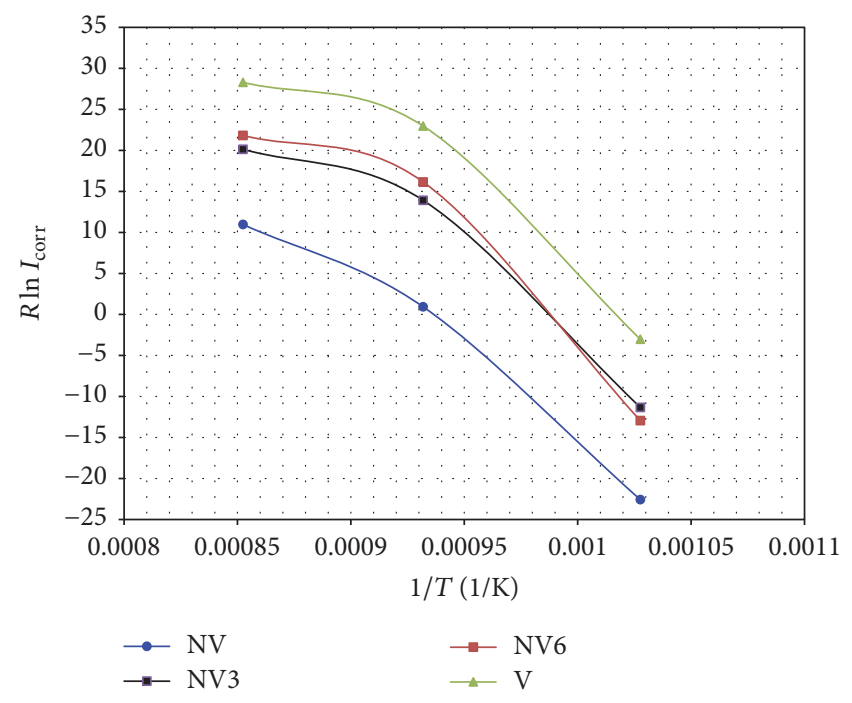

(b)

FIGURE 9: $R \ln \left(I_{\text {corr }}\right)-1 / T$ relationship for Ni evaluated in vanadium salts. (a) Data from the potentiodynamic polarization curves. (b) Data from LPR measurements.

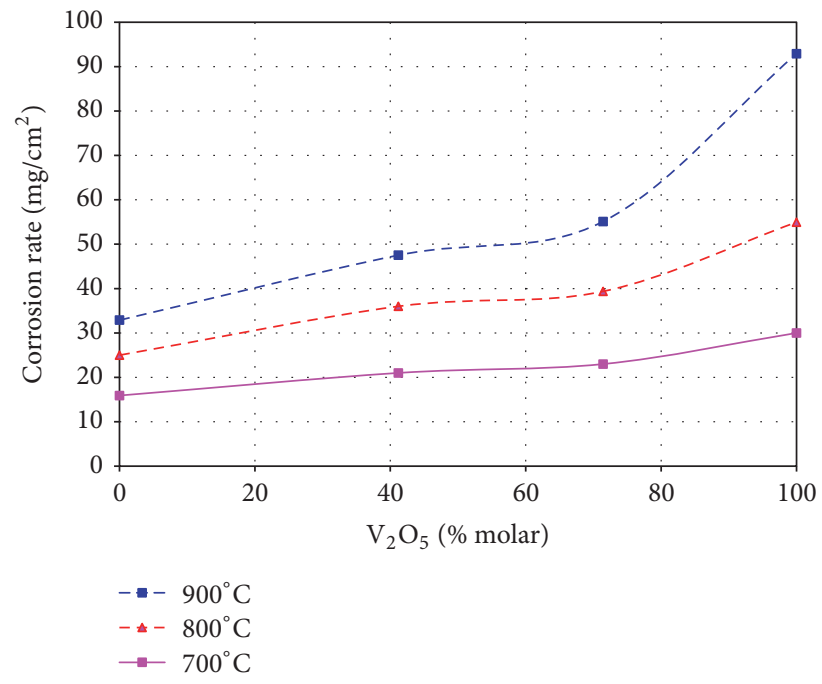

(a)

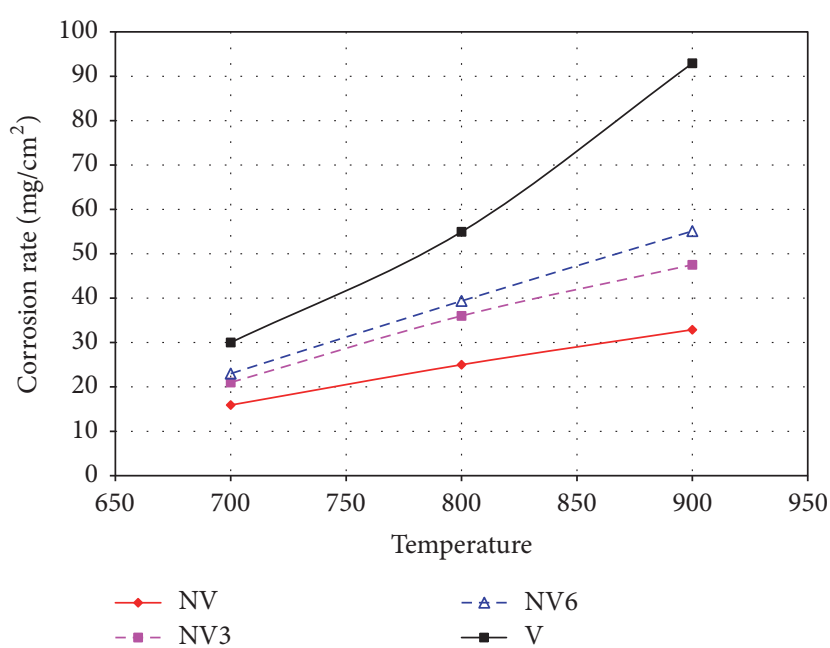

(b)

Figure 10: (a) Effect of the NV: V ratio and (b) temperature on Ni corrosion rate after 100 hours.

but it is clear that the reactivity of the other vanadium salts decreased by one order of magnitude. The drastic increase in the activation energy values shows that the corrosion products adhering to the $\mathrm{Ni}$ surface provide high protection.

3.3. Mass Loss Tests. Figure 10 shows the effect of the different vanadium salts on the corrosion rate of $\mathrm{Ni}$, expressed in terms of weight loss $\left(\mathrm{mg} / \mathrm{cm}^{2}\right)$ at different temperatures after 100 hours of immersion. From the figures it is observed that, at higher exposure times, the Ni behavior in the different vanadium salts shows the same tendency as observed in the previous tests; namely, the aggressiveness of the molten salts increases with the vanadium content and temperature.
Corrosiveness of NV3 and NV6 was similar, being slightly higher with NV6.

Figure 11 shows the cross sectional images of the $\mathrm{Ni}$ samples after being immersed in vanadium salts at 700, 800, and $900^{\circ} \mathrm{C}$ for 100 hours. In all cases similar characteristics are observed. At all temperatures onto Ni surface a nickel oxide layer was observed (in NV3, NV6, and V at $900^{\circ} \mathrm{C}$ it is not very evident), and on it a thick layer of corrosion products rich in $\mathrm{V}, \mathrm{Ni}$, and $\mathrm{O}$. It is clear that nickel was rapidly corroded by the vanadium salts; however the thick layer of corrosion products formed can act as a barrier against the penetration of the corrosive agent.

Regardless of the molten salt, the X-ray diffraction analysis of the corrosion products showed that these were 

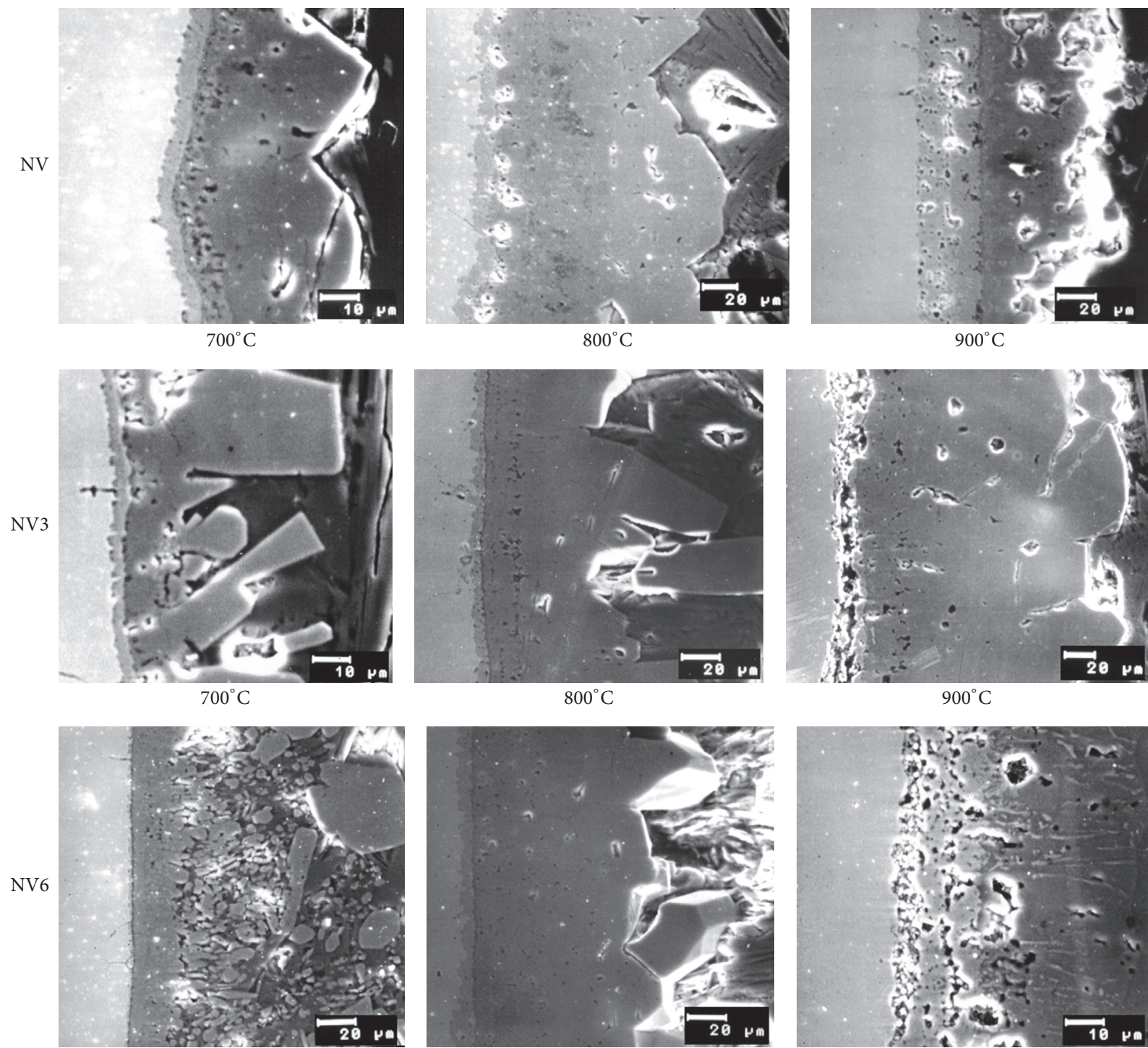

$700^{\circ} \mathrm{C}$

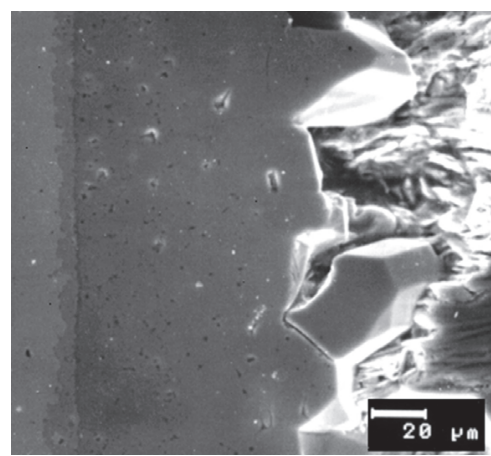

$800^{\circ} \mathrm{C}$

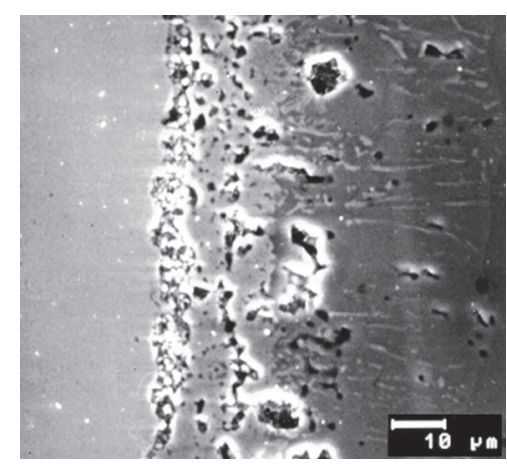

$900^{\circ} \mathrm{C}$

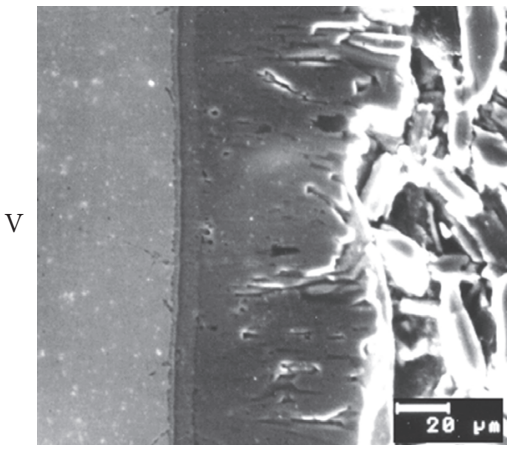

$700^{\circ} \mathrm{C}$

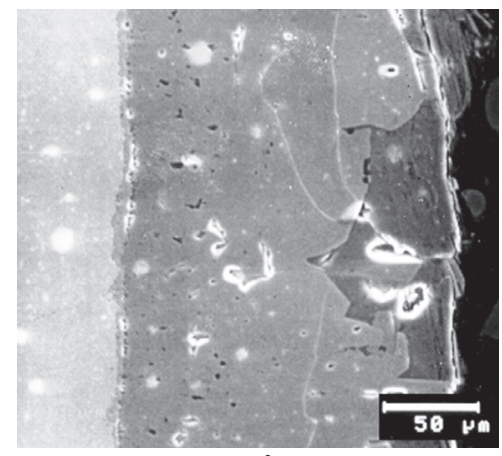

$800^{\circ} \mathrm{C}$

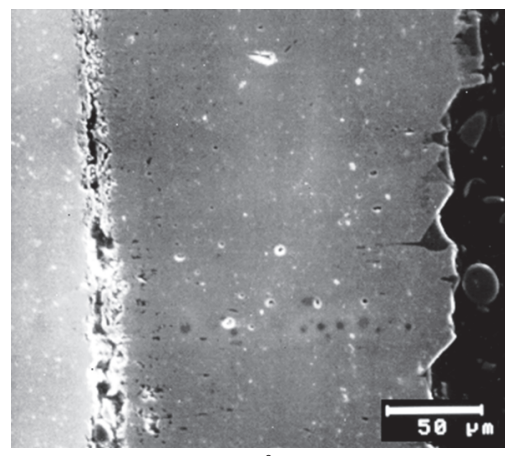

$900^{\circ} \mathrm{C}$

FIgURE 11: Micrographs of the cross sections of Ni exposed to NV3 at $600,700,800$, and $900^{\circ} \mathrm{C}$, during 100 hours.

mainly composed of nickel oxide $(\mathrm{NiO})$ and nickel vanadate $\left(\mathrm{Ni}_{3} \mathrm{~V}_{2} \mathrm{O}_{8}\right)$; similar observations have been made in other studies $[21,22]$. This indicates the high corrosiveness of the vanadium salts because they increase the acidic solubility of the metallic oxides [10]. According to the chemical composition of the vanadium salts used, the Ni degradation occurred according to the following reactions:

$$
2 \mathrm{Ni}+\mathrm{O}_{2} \longrightarrow 2 \mathrm{NiO}
$$




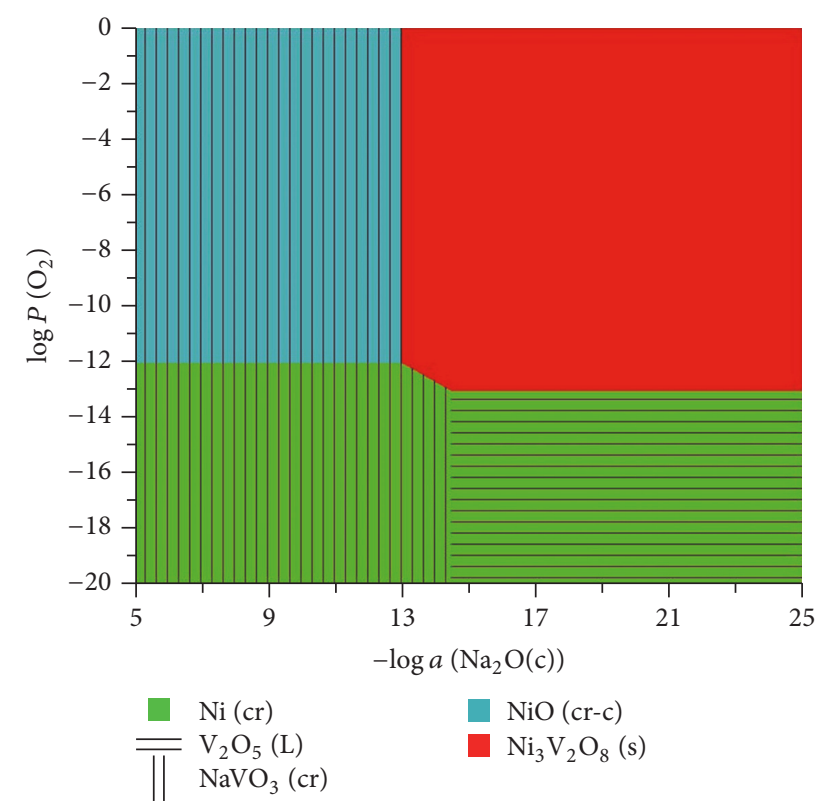

FIgURE 12: Thermodynamic stability diagrams for $\mathrm{Ni}-\mathrm{Na}-\mathrm{V}-\mathrm{O}$ at $900^{\circ} \mathrm{C}$.

$$
\begin{gathered}
3 \mathrm{Ni}+2 \mathrm{NaVO}_{3}+\frac{1}{2} \mathrm{O}_{2} \longrightarrow \mathrm{Ni}_{3} \mathrm{~V}_{2} \mathrm{O}_{8}+\mathrm{Na}_{2} \mathrm{O} \\
3 \mathrm{Ni}+\mathrm{V}_{2} \mathrm{O}_{5}+2 \mathrm{O}_{2} \longrightarrow \mathrm{Ni}_{3} \mathrm{~V}_{2} \mathrm{O}_{8}+\frac{1}{2} \mathrm{O}_{2} \\
3 \mathrm{NiO}+2 \mathrm{NaVO}_{3} \longrightarrow \mathrm{Ni}_{3} \mathrm{~V}_{2} \mathrm{O}_{8}+\mathrm{Na}_{2} \mathrm{O} \\
3 \mathrm{NiO}+\mathrm{V}_{2} \mathrm{O}_{5} \longrightarrow \mathrm{Ni}_{3} \mathrm{~V}_{2} \mathrm{O}_{8}
\end{gathered}
$$

In the corrosion process by vanadium salts in molten state, the melt acts as n-type semiconductors where it is possible that oxygen diffuses as $\mathrm{O}^{-2}$ or $\mathrm{VO}_{3}{ }^{-}$, and the transfer of charge probably involves the redox reaction $\mathrm{V}^{+5} \leftrightarrow \mathrm{V}^{+4}$ $[16,20,23]$. Therefore, any modification to the equilibrium of these processes will affect the corrosiveness of the melt. The performance of a material in a highly corrosive medium depends on the chemical stability of both the metallic elements and their compounds such as oxides and vanadates [22]. Therefore, the observed decrease in the Ni corrosion rate as time elapses (LPR measurements) may be due to the high melting point of the nickel vanadate $\left(1220^{\circ} \mathrm{C}\right)$, which is considered a refractory compound [24]. The presence of this compound may have limited the mobility of aggressive species towards the metal surface.

Because the $\mathrm{Na}_{2} \mathrm{O}$ reduces the acidity of the molten salts, the increase in the corrosion rate observed by increasing the $\mathrm{V}$ concentration is consistent with the reactions mentioned above, since at higher $\mathrm{V}$ content the proportion of $\mathrm{Na}_{2} \mathrm{O}$ formed is reduced. Based on the above reactions, in addition to the equilibrium, $2 \mathrm{NaVO}_{3}=\mathrm{V}_{2} \mathrm{O}_{5}+\mathrm{Na}_{2} \mathrm{O}$, the phase stability diagram shown in Figure 12 was constructed, according to the procedure indicated elsewhere [25].

According to the diagram, it is observed that, in a wide range of partial oxygen pressures equivalent to the melt-atmosphere interface $(\approx 0.21 \mathrm{~atm})$ and to the melt-metal interface $\left(\approx 1 \times 10^{-4}\right.$ to $1 \times 10^{-12}$ atm), if acid vanadium salts (NV3, NV6, and V) are present the only reaction product will be $\mathrm{Ni}_{3} \mathrm{~V}_{2} \mathrm{O}_{8}$ and, on the contrary, in low acidity salts (NV) the additional presence of $\mathrm{NiO}$ is possible. This is congruent with the micrographs shown in Figure 11. In these it is observed that only in the presence of $\mathrm{NV}$ at $900^{\circ} \mathrm{C}$ a $\mathrm{NiO}$ thick layer is evident onto Ni surface. According to other studies the low aggressiveness in $\mathrm{NV}$ melts is due to the fact that during its reaction with $\mathrm{Ni}$ or $\mathrm{NiO}$, in addition to forming the metallic vanadate, it also generates $\mathrm{Na}_{2} \mathrm{O}$ as a byproduct; this further reduces the acidity of the melt and affects the charge transport because the $\mathrm{V}^{5+}: \mathrm{V}^{4+}$ ratio is modified [11]. In contrast, the reaction of $\mathrm{Ni}$ or $\mathrm{NiO}$ with $\mathrm{V}$ only generates the metallic vanadate without any modification in the acidity of the melt. In the case of the NV3 and NV6 species the decrease in their corrosiveness, compared to that of the $\mathrm{V}$, is due to the presence of $\mathrm{NV}$ which reduces the acidity of the mixture. However, its aggressiveness is much greater than that shown by $\mathrm{NV}$, because these complex vanadates in molten state also have the ability to absorb a large amount of oxygen which provides a rapid transport of oxygen to the metal surface $[12,19]$.

The high initial reactivity of $\mathrm{Ni}$ in the presence of vanadium salts has a beneficial effect because it forms a highly stable refractory phase, $\mathrm{Ni}_{3} \mathrm{~V}_{2} \mathrm{O}_{8}$, which reduces the corrosiveness of the melt by trapping the vanadium and blocking the migration of nickel ions [3, 23, 26], and the stability of the refractory phase still prevails in the presence of $\mathrm{Na}_{2} \mathrm{SO}_{4}$ [2]. The results obtained are congruent with other studies where $\mathrm{NiO}$ has been proposed as a corrosion inhibitor in vanadium-rich molten salts [2, 3, 24], or Ni-derivatives to remove vanadium compounds [26]. Notwithstanding the above, in the case of nickel-based alloys with a multielement chemical composition the results may be different due to synergistic dissolution reactions between the different oxides developed [11, 27-29].

\section{Conclusions}

From the results of this work, it can be concluded that Ni shows a high reactivity in vanadium molten salts. An increase in both the acidity and temperature of the melt causes a noticeable increase in the current densities of the anodic and cathodic reactions due to an increase in the transport of charge by the presence of vanadium in multivalent state $\left(\mathrm{V}^{5+}\right.$, $\left.\mathrm{V}^{+4}\right)$. Corrosion products form a dense and protective barrier onto Ni surface which limits the access of the vanadium salts since no presence of $\mathrm{Ni}$ into vanadium melt was observed. The corrosion products increase the activation energy of the corrosive process by at least one order of magnitude. The initial reactivity of the nickel forms a highly stable refractory phase that reduces the corrosiveness of the melt by trapping the vanadium and blocking the migration of nickel ions. The corrosiveness of the vanadium salts increased in the order $\mathrm{NV}<\mathrm{NV} 3<\mathrm{NV} 6<\mathrm{V}$. Low corrosiveness of the NV is due to the fact that during the corrosion process the $\mathrm{Na}_{2} \mathrm{O}$ is released as a reaction byproduct, and the melt basicity is increased affecting the charge transport and decreasing the 
$\mathrm{V}^{5+}: \mathrm{V}^{4+}$ ratio. On the other hand, the high corrosiveness of $\mathrm{V}$ is due to the fact that its corrosion reactions only form metallic vanadates which do not affect the melt acidity.

\section{Conflicts of Interest}

The authors declare that there are no conflicts of interest regarding the publication of this paper.

\section{Acknowledgments}

Financial support from Consejo Nacional de Ciencia y Tecnología (CONACYT, México) (Project 159898) is gratefully acknowledged.

\section{References}

[1] X. Montero and M. C. Galetz, "Inhibitors and coatings against vanadate-containing oil ash corrosion of boilers," Surface and Coatings Technology, vol. 304, pp. 211-221, 2016.

[2] E. Rocca, L. Aranda, and M. Molière, "Chemistry of ashdeposits on gas turbines hot parts: Reactivity of nickel, zinc and iron oxides in (Na, V, S) molten salts," Materials Science Forum, vol. 595-598, pp. 169-176, 2008.

[3] E. Rocca, P. Steinmetz, and M. Moliere, "Revisiting the inhibition of vanadium-induced hot corrosion in gas turbines," Journal of Engineering for Gas Turbines and Power, vol. 125, no. 3, pp. 664-669, 2003.

[4] C. Cuevas-Arteaga, J. Uruchurtu-Chavarín, J. González, G. Izquierdo-Montalvo, J. Porcayo-Calderón, and U. CanoCastillo, "Corrosion evaluation of Alloy 800 in sulfate/vanadate molten salts," Corrosion, vol. 60, no. 6, pp. 548-560, 2004.

[5] H. Singh, D. Puri, and S. Prakash, "An overview of $\mathrm{Na}_{2} \mathrm{SO}_{4}$ and/or $\mathrm{V}_{2} \mathrm{O}_{5}$ induced hot corrosion of Fe-and Ni-based superalloys," Reviews on Advanced Materials Science, vol. 16, pp. 2750, 2007.

[6] J. G. Gonzalez-Rodriguez, S. Haro, A. Martinez-Villafañe, V. M. Salinas-Bravo, and J. Porcayo-Calderon, "Corrosion performance of heat resistant alloys in $\mathrm{Na}_{2} \mathrm{SO}_{4}-\mathrm{V}_{2} \mathrm{O}_{5}$ molten salts," Materials Science and Engineering A, vol. 435-436, pp. 258-265, 2006.

[7] W. J. Quadakkers and M. J. Bennet, "Oxidation induced lifetime limits of thin walled, iron based, alumina forming, oxide dispersion strengthened alloy components," Materials Science and Technology, vol. 10, no. 2, pp. 126-131, 1994.

[8] I. Wolf, H. J. Grabke, and P. Schmidt, "Carbon transport through oxide scales on Fe-Cr alloys," Oxidation of Metals, vol. 29, no. 34, pp. 289-306, 1988.

[9] H. W. Grünling and R. Bauer, "The role of silicon in corrosionresistant high temperature coatings," Thin Solids Films, vol. 95, no. 1, pp. 3-20, 1982.

[10] Y. S. Zhang and R. A. Rapp, "Solubilities of $\mathrm{CeO}_{2}, \mathrm{HfO}_{2}$ and $\mathrm{Y}_{2} \mathrm{O}_{3}$ in fused $\mathrm{Na}_{2} \mathrm{SO}_{4}-30$ mol\% $\mathrm{NaVO}_{3}$ and $\mathrm{CeO}_{2}$ in Pure $\mathrm{Na}_{2} \mathrm{SO}_{4}$ at 900॰C," Corrosion, vol. 43, no. 6, pp. 348-352, 1987.

[11] Y.-S. Hwang and R. A. Rapp, "Thermochemistry and solubilities of oxides in sodium sulfate-vanadate solutions," Corrosion, vol. 45, no. 11, pp. 933-937, 1989.

[12] G. W. Cunningham and A. d. S. Brasunas, "The effects of contamination by vanadium and sodium compounds on the air-corrosion of stainless steel," Corrosion, vol. 12, pp. 389-405, 1956.
[13] A. Wong, R. I. Marchan, and L. Martinez, "Molten salt corrosion of heat resistant alloys," in Proceedings of the CORROSION 95, Paper 465, NACE International, Houston, TX, USA, 1995.

[14] A. Wong-Moreno, Y. Mujica, and L. Martinez, "High temperature corrosion enhanced by fuel oil ash seposits," in Proceedings of the CORROSION 94, paper 185, NACE International, Houston, TX, USA, 1994.

[15] J. Porcayo-Calderon, V. M. Salinas Bravo, R. A. Rodríguez-Díaz, and L. Martinez-Gomez, "Effect of the $\mathrm{NaVO}_{3}-\mathrm{V}_{2} \mathrm{O}_{5}$ ratio on the high temperature corrosion of Chromium," International Journal of Electrochemical Science, vol. 10, pp. 4928-4945, 2015.

[16] R. B. Dooley and J. R. Wilson, "The Corrosion of a 50Cr$50 \mathrm{Ni}$ alloy in liquid vanadate systems in the temperature range 750-950॰C," Journal of Engineering for Power, vol. 97, no. 3, pp. $422-428,1975$.

[17] R. Mittelstadt and K. Schwerdtfeger, "The dependence of the oxidation state of vanadium on the oxygen pressure in melts of VOx, $\mathrm{Na}_{2} \mathrm{O}-\mathrm{VOx}$, and $\mathrm{CaO}-\mathrm{SiO}_{2}$-VOx," Metallurgical Transactions $B$, vol. 21, no. 1, pp. 111-120, 1990.

[18] I. B. Singh, "Corrosion and sulphate ion reduction studies on $\mathrm{Ni}$ and $\mathrm{Pt}$ surfaces in with and without $\mathrm{V}_{2} \mathrm{O}_{5}$ in $(\mathrm{Li}, \mathrm{Na}, \mathrm{K})_{2} \mathrm{SO}_{4}$ melt," Corrosion Science, vol. 45, no. 10, pp. 2285-2292, 2003.

[19] N. D. Phillips and C. L. Wagoner, "Use of differential thermal analysis in exploring minimum temperature limits of oil ash corrosion," Corrosion, vol. 17, no. 8, pp. 396t-400t, 1961.

[20] E. Chassagneux and G. Thomas, "Studies on $\mathrm{V}_{2} \mathrm{O}_{5}$ induced hot corrosion," Materials Chemistry and Physics, vol. 17, no. 3, pp. 273-284, 1987.

[21] S.-I. Muroi, M. Someno, and M. Kobayashi, "Corrosion products of pure metals in $\mathrm{V}_{2} \mathrm{O}_{5}$ Melt," Tetsu-To-Hagane, vol. 58, no. 6, pp. 773-786, 1972.

[22] O. Sotelo-Mazón, J. Porcayo-Calderon, C. Cuevas-Arteaga, J. J. Ramos-Hernandez, J. A. Ascencio-Gutierrez, and L. MartinezGomez, "EIS Evaluation of $\mathrm{Fe}, \mathrm{Cr}$, and $\mathrm{Ni}$ in $\mathrm{NaVO}_{3}$ at $700 \circ \mathrm{C}$," Journal of Spectroscopy, vol. 2014, 10 pages, 2014.

[23] E. Chassagneux, G. Thomas, and M. Soustelle, "Corrosion of Nickel by $\mathrm{V}_{2} \mathrm{O}_{5}$ : Critical phenomenon due to $\mathrm{O}_{2}$ pressure," Materials Science and Engineering, vol. 87, pp. 379-382, 1987.

[24] E. Rocca, L. Aranda, M. Moliere, and P. Steinmetz, "Nickel oxide as a new inhibitor of vanadium-induced hot corrosion of superalloys-comparison to MgO-based inhibitor," Journal of Materials Chemistry, vol. 12, no. 12, pp. 3766-3772, 2002.

[25] J. J. Ramos-Hernandez, J. Porcayo-Calderon, V. M. SalinasBravo, C. D. Arrieta-Gonzalez, J. G. Gonzalez-Rodriguez, and L. Martinez-Gomez, "Phase stability diagrams for high temperature corrosion processes," Mathematical Problems in Engineering, vol. 2013, Article ID 542061, 7 pages, 2013.

[26] N. Di Salvia, M. P. Malavasi, G. Di Salvia, and A. Vaccari, "Formation of $\mathrm{Ni}$ and $\mathrm{Mg}$ vanadates during the flameless oxycombustion of heavy fuels," Fuel Processing Technology, vol. 138, pp. 534-539, 2015.

[27] R. A. Rapp, "Hot corrosion of materials," Pure and Applied Chemistry, vol. 62, pp. 113-122, 1990.

[28] R. A. Rapp, "Hot corrosion of materials: A fluxing mechanism?" Corrosion Science, vol. 44, no. 2, pp. 209-221, 2002.

[29] Y. Longa-Nava, Y. S. Zhang, M. Takemoto, and R. A. Rapp, "Hot Corrosion of Nickel-Chromium and Nickel-ChromiumAluminum Thermal-Spray Coatings by Sodium Sulfate-Sodium Metavanadate Salt," Corrosion, vol. 52, no. 9, pp. 680-689, 1996. 

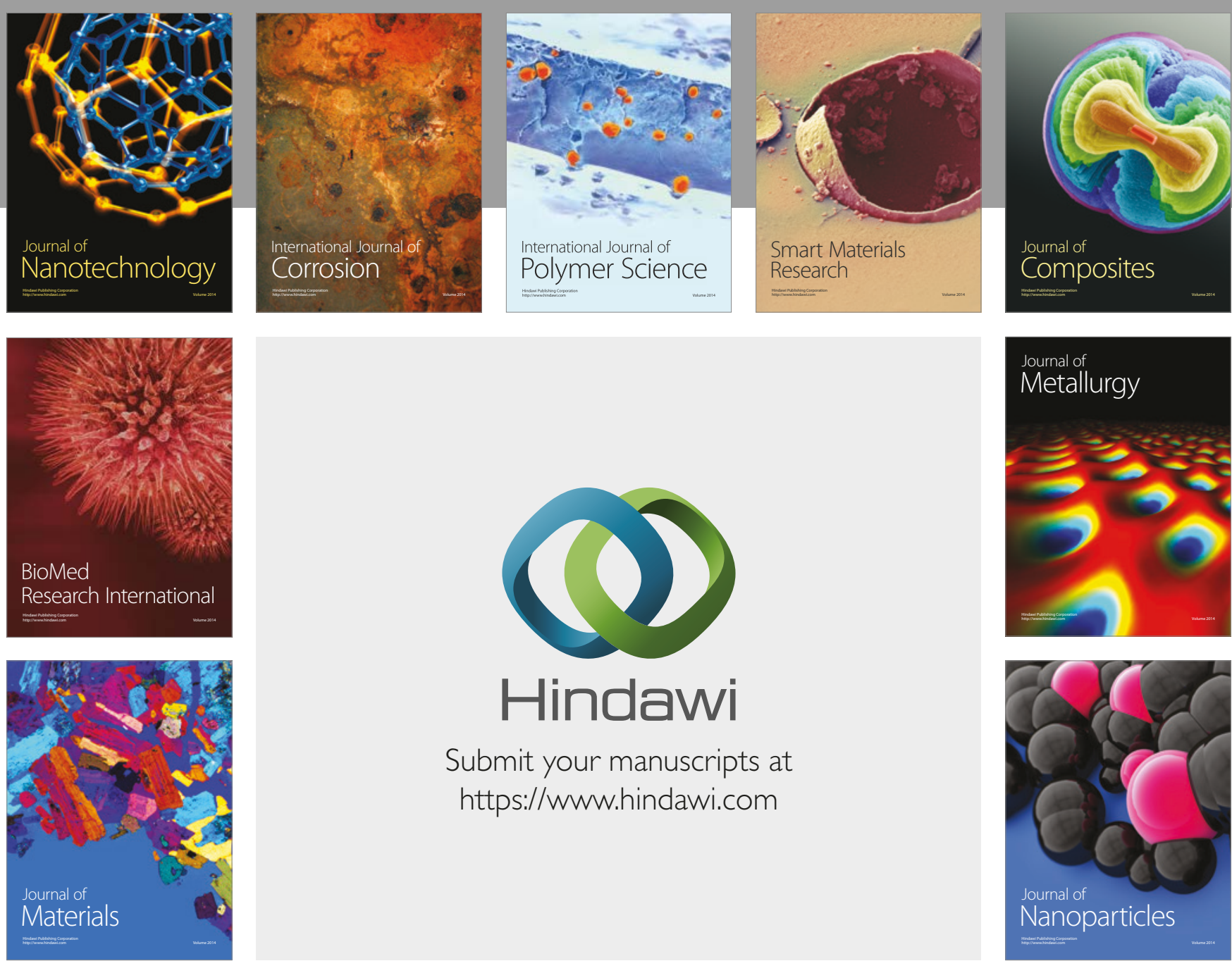

\section{Hindawi}

Submit your manuscripts at

https://www.hindawi.com
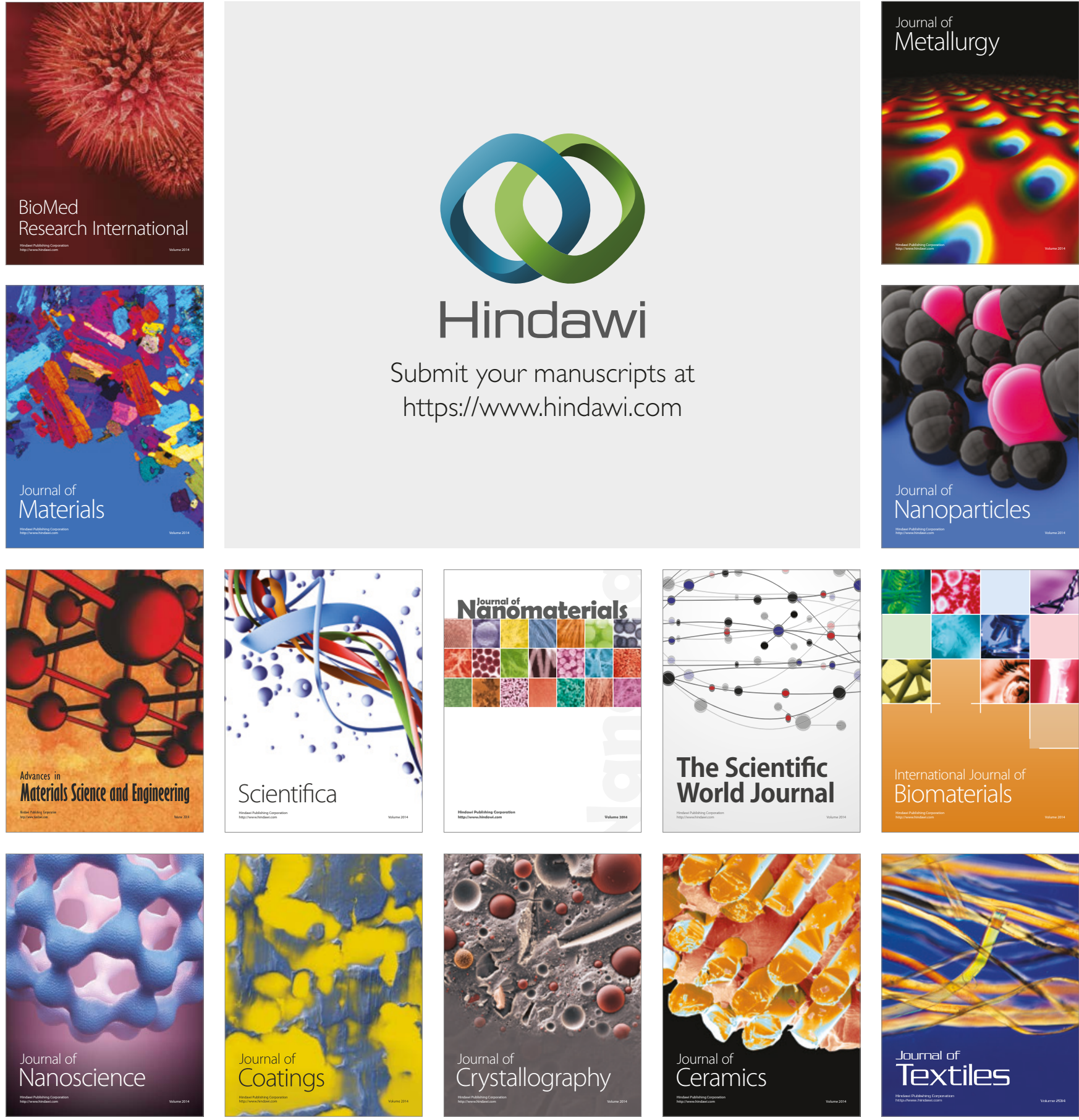

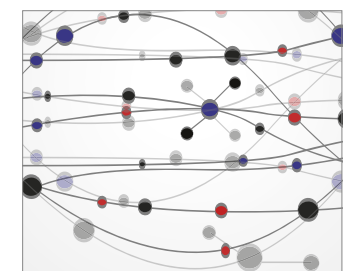

The Scientific World Journal
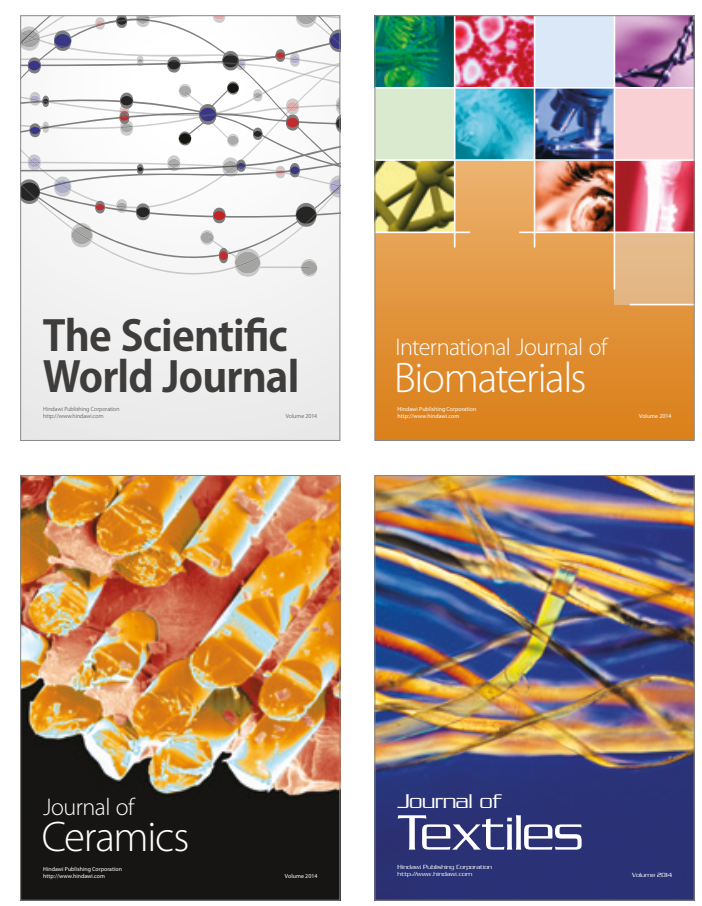